Case report

\title{
A rare cause of non-ST elevation myocardial infarction related to total coronary artery occlusion: Dual RCA
}

\author{
Belma Kalaycı ${ }^{*}$, Muhammed Rasit Sayin ${ }^{1}$ \\ Bülen Ecevit University Hospital, Department of Cardiology, 61600 Zonguldak, Turkey
}

\section{A R T I C L E I N F O}

\section{Article history:}

Received 10 May 2016

Received in revised form 14 June 2016

Accepted 14 June 2016

Available online 21 June 2016

\section{Keywords:}

Dual right coronary artery

Myocardial infarction

Double RCA

\begin{abstract}
A B S T R A C T
Dual right coronary artery (RCA) is one of the rarest coronary anomalies. We presented a 61-year-old male referred with non-ST-segment elevation myocardial infarction. Angiogram revealed a stenosis-free RCA and another RCA with total occlusion of the proximal segment and originating from the same aortic sinus was also found. Total coronary occlusion increases mortality in patients with NSTEMI. In this paper we discussed that the presence of dual RCA may actually prevent undesired cardiac events.

(c) 2016 The Society of Cardiovascular Academy. Production and hosting by Elsevier B.V. All rights reserved. This is an open access article under the CC BY-NC-ND license (http://creativecommons.org/licenses/by-nc-nd/4.0/).
\end{abstract}

\section{Introduction}

The prevalence of coronary anomalies is reported to be $0.2-1.4 \%$ of the general population, ${ }^{1}$ and dual right coronary artery (RCA) is one of the rarest coronary anomalies. The incidence of dual RCA varies from $0.01 \%$ in conventional coronary angiography to $0.07 \%$ in coronary angiography. ${ }^{2}$

Acute coronary occlusion (ACO) is responsible for ST-segment elevation myocardial infarction; however, ACO may also cause non-STsegment elevation myocardial infarction (NSTEMI). ${ }^{3}$ Previous studies have reported that ACO increases mortality in patients with NSTEMI. ${ }^{4}$ However, there is no consensus about how to predict which patients are at the highest risk. Some studies have suggested that electrocardiograms may help identify NSTEMI related to total coronary artery occlusion. ${ }^{5,6}$ In this report, we discuss a case of dual RCA, a rare cause of NSTEMI related to RCA occlusion. Dual RCA may prevent undesired cardiac events when the second RCA is patent.

\section{Case report}

A 61-year-old male had a history of hypertension, smoking, and chronic obstructive pulmonary disease who admitted to hospital. He had no history of coronary artery disease and was only taking diltiazem for hypertension. He admitted to the hospital with acute chest pain. He has been experiencing angina pectoris for $10 \mathrm{~h}$. Electrocardiography

\footnotetext{
* Corresponding author. Tel.: + 905059136012.

E-mail addresses: drbelma@hotmail.com (B. Kalaycı), rasitsayin@gmail.com (M.R. Sayin).

1 Tel.: + 905309112885 .

Peer review under responsibility of The Society of Cardiovascular Academy.
}

(ECG) was not remarkable except for minimal ST-segment depression in leads V5 and V6 (Fig. 1). Serum biochemistry was normal except for mildly increased cardiac enzymes and troponin. The level of troponin I was $0.1 \mathrm{ng} / \mathrm{ml}(0-0.03 \mathrm{ng} / \mathrm{ml})$. He was referred to our center for coronary angiography due to NSTEMI. Echocardiography revealed hypokinesia of septum and normal left ventricular systolic function. Coronary angiogram was planned at the same day. The left anterior descending (LAD) artery showed intermediate stenosis in the middle segment, and the RCA was determined to have a retrograde collateral supply from the LAD artery, as identified by angiography (Fig. 2a). A plaque in the proximal segment of the major obtuse marginal branch of the left circumflex (LCX) artery was showed by angiography (Fig. 2b). Fluoroscopy (the left anterior oblique [LAO] projection) also revealed a stenosis-free RCA (RCA1) originating from the right aortic sinus (Fig. 3a). However, another RCA (RCA2) with total occlusion of the proximal segment and originating from the same aortic sinus was also found (Fig. 3b). RCA2 had just a small conus branch. Left ventriculography showed hypokinesia of inferior segment. Echocardiography revealed decreased systolic function (ejection fraction 40\%) and hypokinesia of inferior segment. He had new onset angina and high troponin level. Therefore we decided to perform percutaneous coronary intervention for the stenotic RCA. However, the patient refused, so we instead followed him medically.

\section{Discussion}

Dual RCA is one of the rarest coronary anomalies, and until now there has been no consensus on the definition of dual RCA. To understand more about dual RCA, we searched the literature using the following keywords: "double right coronary artery," "duplicated right coronary artery," "dual right coronary artery," and "split right coronary artery". ${ }^{1}$ According to Sawaya et al. ${ }^{7}$ a split or double RCA is the same 


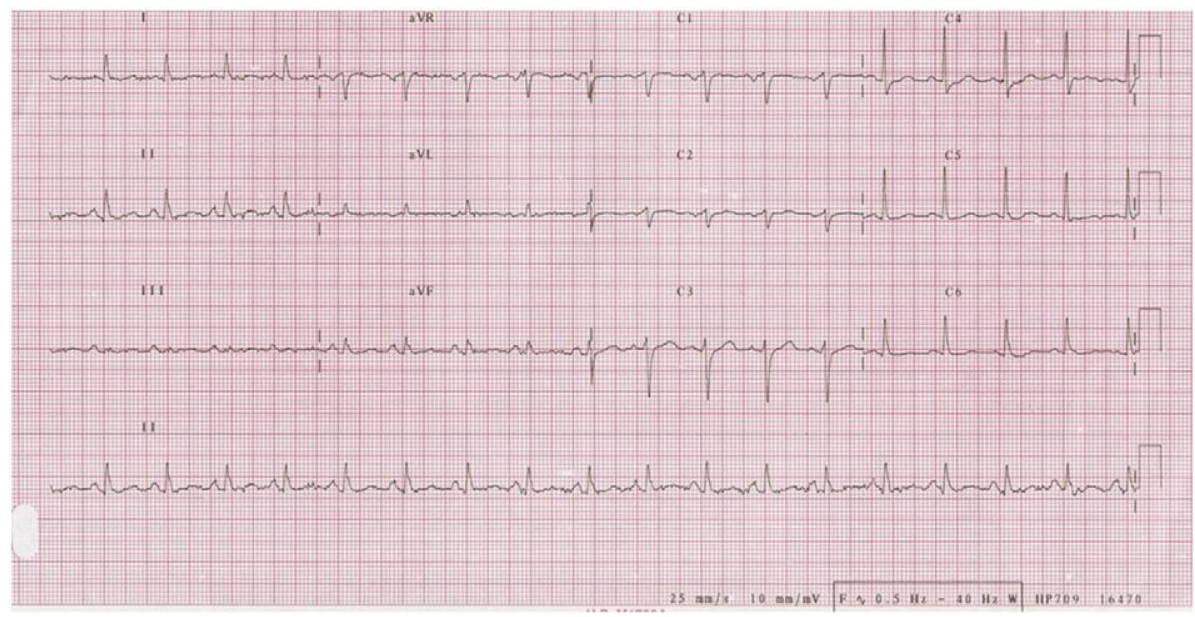

Fig. 1. The results of ECG were unremarkable except for minimal ST-segment depression in leads V5 and V6.

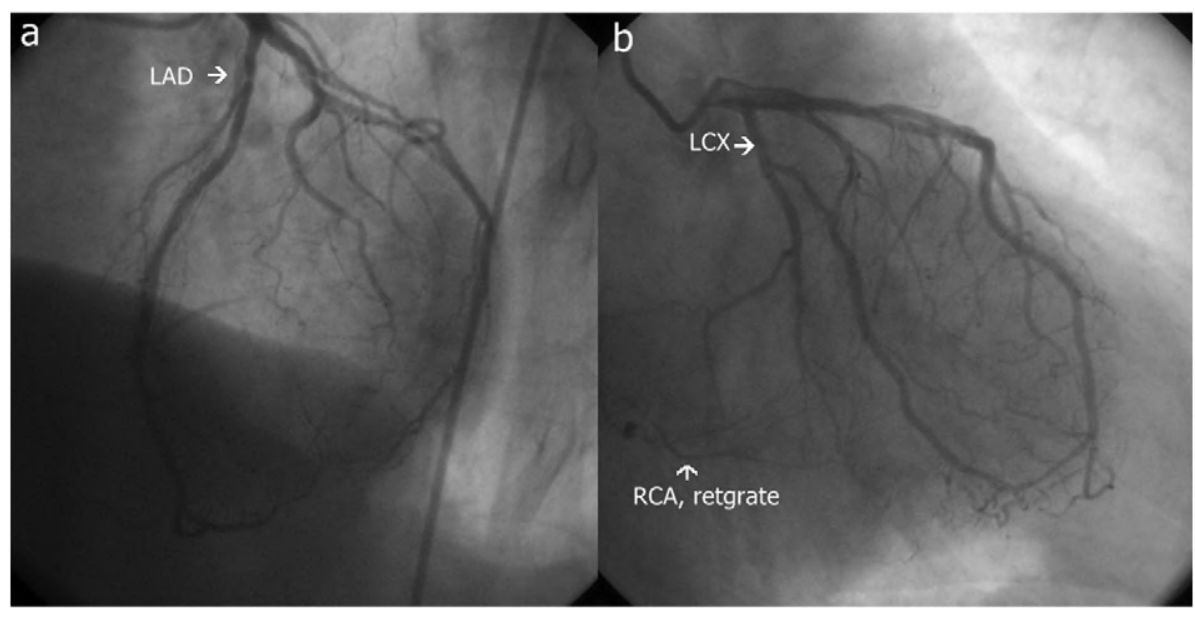

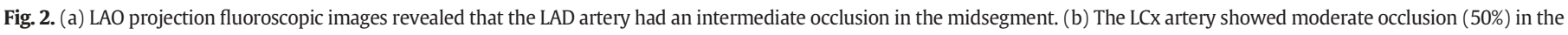
proximal segment on the major obtuse marginal branch in the right caudal projection.

anomaly, and in reality there is only one RCA. Other authors define "double RCA" as RCAs that originate separately from two different ostia. ${ }^{8}$ However, most cases are reported as double RCAs whether they originate from the same ostia or not.
Bahrmann et al. ${ }^{6}$ showed that patients with NSTEMI related to ACO had more frequent inferolateral or posterolateral lesions, more collaterals, larger infarcts, and more non-fatal reinfarctions compared with non-AOC patients. In general, there are angiographically visible

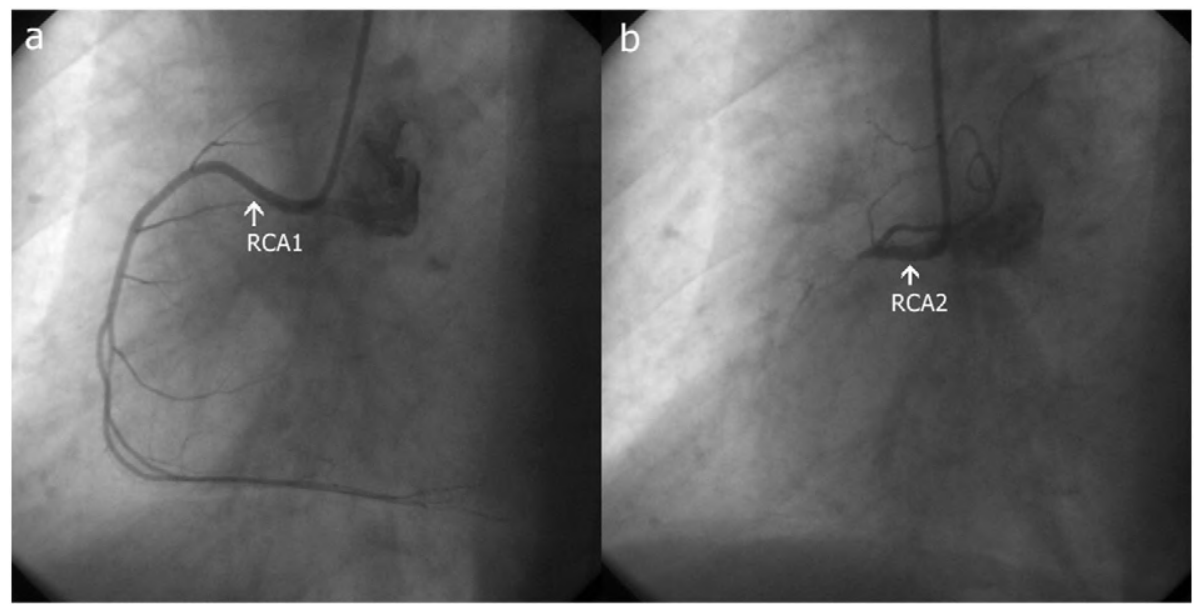

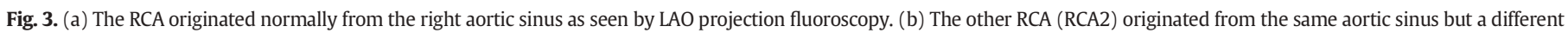
ostium with total occlusion. 
collaterals in these patients, and patients with NSTEMI related to ACO and absent collaterals had a significantly higher risk of major cardiac events within six months. ${ }^{6}$ Predicting which patients with NSTEMI related to ACO are at increased risk for additional infractions is complicated and requires further investigation.

One case was reported previously, and the patient presented with an atypical double RCA and acute inferior myocardial infarction. ${ }^{9}$ However, a dual RCA has not been reported in a patient with NSTEMI related to right coronary total occlusion. Patients with NSTEMI are at increased risk of acute coronary occlusion, and the presence of dual RCA may actually prevent undesired cardiac events. In our case he had new onset angina and high troponin level. So we decided to perform percutaneous coronary intervention for the stenotic RCA because of his ongoing angina. That stenotic RCA might be chronic total occlusion and the culprit lesion may be a different coronary artery. In this case we needed to know the presence of viable myocardium in RCA segments and after that we decided the therapy of the patient. But he refused our medical advises.

\section{Conclusions}

We reported a patient with dual RCA originating from the same right aortic sinus from two ostia, and that presented with NSTEMI related to RCA occlusion. In this case, the dual RCA may have prevented ST-segment elevation myocardial infarction. However, this hypothesis requires further investigation and testing.

The English in this document has been checked by at least two professional editors, both native speakers of English. For a certificate, please see: http://www.textcheck.com/certificate/0HZp28.

\section{Declaration of conflicting interests}

The authors declared no conflicts of interest with respect to the authorship and/or publication of this article.

\section{References}

1. Chen YF, Chien TM, Chen CW, Lin CC, Lee CS. Double right coronary artery or split right coronary artery? Int J Cardiol 2012;154(3):243-245.

2. Harikrishnan S, Jacob SP, Tharakan J, et al. Congenital coronary anomalies of origin and distribution in adults: a coronary arteriographic study. Indian Heart J 2002;54(3): 271-275.

3. Wang TY, Zhang M, Fu Y, et al. Incidence, distribution, and prognostic impact of occluded culprit arteries among patients with non-ST-elevation acute coronary syndromes undergoing diagnostic angiography. Am Heart J 2009;157(4):716-723.

4. Kim MC, Ahn Y, Rhew SH, et al. Impact of total occlusion of an infarct-related artery on long-term mortality in acute non-ST-elevation myocardial infarction patients who underwent early percutaneous coronary intervention. Int Heart J 2012;53(3): 160-164.

5. Roleder T, Smolka G, Pysz P, Kozyra A, Ochala A. Non-ST elevation myocardial infarction related to total coronary artery occlusion - prevalence and patient characteristics. Postepy Kardiol Interwencyjnej 2015;11(1):9-13.

6. Bahrmann P, Rach J, Desch S, Schuler GC, Thiele H. Incidence and distribution of occluded culprit arteries and impact of coronary collaterals on outcome in patients with non-ST-segment elevation myocardial infarction and early invasive treatment strategy. Clin Res Cardiol 2011;100(5):457-467.

7. Sawaya FJ, Sawaya JI, Angelini P. Split right coronary artery: its definition and its territory. Tex Heart Inst J 2008;35(4):477-479.

8. Yoon SR, Jung AY, Choi SH, Bang OY, Lee NH. Anomalous double right coronary arteries: characteristic multidetector-row computed tomography findings. J Comput Assist Tomogr 2010;34(5):666-669.

9. Acet H, Ozyurtlu F, Bilik MZ, Ertas F. A rare coronary anomaly: atypical double right coronary artery with an acute inferior myocardial infarction. Korean Circ J 2012;42(3): 208-211. 